\title{
Outcomes of trastuzumab therapy in HER2-positive early breast cancer patients: extended follow-up of JBCRG-cohort study 01
}

\author{
Hiroyasu Yamashiro ${ }^{1}$ (D) Hiroji Iwata ${ }^{2} \cdot$ Norikazu Masuda $^{3} \cdot$ Naohito Yamamoto $^{4} \cdot$ Reiki Nishimura $^{5}$. \\ Shoichiro Ohtani ${ }^{6} \cdot$ Nobuaki Sato $^{7} \cdot$ Masato Takahashi $^{8} \cdot$ Takako Kamio $^{9} \cdot$ Kosuke Yamazaki $^{10} \cdot$ Tsuyoshi Saito $^{11}$. \\ Makoto Kato ${ }^{12} \cdot$ Tecchuu Lee $^{13} \cdot$ Katsumasa Kuroi $^{14} \cdot$ Toshimi Takano $^{15} \cdot$ Shinji Yasuno $^{16} \cdot$ Satoshi Morita $^{17}$. \\ Shinji Ohno ${ }^{18} \cdot$ Masakazu Toi ${ }^{19}$
}

Received: 19 October 2019 / Accepted: 27 January 2020 / Published online: 14 February 2020

(c) The Author(s) 2020

\begin{abstract}
Background Previous large trials of trastuzumab (TZM) demonstrated improved outcomes in patients with HER2-positive early breast cancer. However, its effectiveness and safety in Japanese patients is not yet clear. Recently, new anti-HER 2 agents were developed to improve treatment outcomes, but the patient selection criteria remain controversial.

Purpose The aim of this study was to evaluate the long-term effectiveness of TZM therapy as perioperative therapy for HER2-positive operable breast cancer in daily clinical practice and to create a recurrence prediction model for therapeutic selection.

Methods An observational study was conducted in Japan (UMIN000002737) to observe the prognosis of women $(n=2024)$ with HER2-positive invasive breast cancer who received TZM for stage I-III C disease between July 2009 and June 2011. Moreover, a recurrence-predicting model was designed to evaluate the risk factors for recurrence.

Results The 5- and 10-year disease-free survival (DFS) rates were 88.9 (95\% CI 87.5-90.3\%) and 82.4\% (95\% CI 79.2$85.6 \%$ ), respectively. The 5- and 10-year overall survival (OS) rates were 96\% (95\% CI 95.1-96.9\%) and 92.7\% (95\% CI 91.1-94.3\%), respectively. Multivariate analysis revealed that the risk factors for recurrence were an age of $\geq 70$ years, T2 or larger tumors, clinically detected lymph node metastasis, histological tumor diameter of $>1 \mathrm{~cm}$, histologically detected lymph node metastasis $(\geq \mathrm{n} 2)$, and the implementation of preoperative treatment. The 5-year recurrence rate under the standard treatment was estimated to be $>10 \%$ in patients with a score of 3 or greater on the recurrence-predicting model.

Conclusion The recurrence-predicting model designed in this study may improve treatment selection of patients with stage I-III C disease. However, further studies are needed to validate the scores generated by this model.
\end{abstract}

Keywords Breast cancer $\cdot$ HER2-positive breast cancer $\cdot$ Cohort study $\cdot$ Trastuzumab $\cdot$ Prediction model

\section{Introduction}

Several randomized trials of trastuzumab (TZM) have demonstrated improved outcomes in patients with HER2positive early breast cancer (EBC) [1-4]. We previously conducted the JBCRG C-01 cohort study, and reported the efficacy and safety of perioperative trastuzumab therapy

Electronic supplementary material The online version of this article (https://doi.org/10.1007/s12282-020-01057-4) contains supplementary material, which is available to authorized users.

Hiroyasu Yamashiro

yamashiro.bcs@gmail.com

Extended author information available on the last page of the article for HER2-positive EBC [5]. However, the long-term outcomes are not yet clear. Recently, perioperative therapy for HER2-positive EBC has been improved via attempts to eliminate anthracycline [1, 6, 7], the development of antiHER2 agents, such as neratinib [8] and pertuzumab [9], and shortening of the trastuzumab administration duration [10-12]. The current issue is to distinguish patients who require more potent treatment from those for whom administration must be de-escalated. Furthermore, due to the increased options for post-recurrence treatment [13, 14], there is a growing need to carry out surveillance for recurrence on an appropriate schedule. In this study, the effectiveness of TZM therapy as perioperative therapy for HER2-positive operable breast cancer in daily clinical 
Table 1 Patient characteristics and treatment

\begin{tabular}{|c|c|c|}
\hline & Number & $(\%)$ \\
\hline Total & 1981 & 100.0 \\
\hline \multicolumn{3}{|l|}{ Age } \\
\hline$<35$ & 70 & 3.5 \\
\hline $35-49$ & 554 & 28.0 \\
\hline $50-59$ & 713 & 36.0 \\
\hline $60-69$ & 501 & 25.3 \\
\hline$\geq 70$ & 143 & 7.2 \\
\hline Mean, SD & 54.3 & 10.7 \\
\hline Max, Min & 18 & 86 \\
\hline \multicolumn{3}{|l|}{ Menopausal state } \\
\hline Premenopause & 698 & 35.2 \\
\hline Postmenopause & 1283 & 64.8 \\
\hline \multicolumn{3}{|l|}{ Tumor stage at initial diagnosis } \\
\hline $\mathrm{TX}$ & 5 & 0.3 \\
\hline Tis & 27 & 1.4 \\
\hline T0 & 8 & 0.4 \\
\hline $\mathrm{T} 1$ & 637 & 32.2 \\
\hline $\mathrm{T} 2$ & 1030 & 52.0 \\
\hline $\mathrm{T} 3$ & 172 & 8.7 \\
\hline $\mathrm{T} 4$ & 102 & 5.1 \\
\hline \multicolumn{3}{|l|}{ Nodal status at initial diagnosis } \\
\hline NX & 4 & 0.2 \\
\hline No & 1131 & 57.1 \\
\hline $\mathrm{N} 1$ & 673 & 34.0 \\
\hline $\mathrm{N} 2$ & 130 & 6.6 \\
\hline N3 & 42 & 2.1 \\
\hline NA & 1 & 0.1 \\
\hline \multicolumn{3}{|l|}{ Tumor grade } \\
\hline 1 & 179 & 9.8 \\
\hline 2 & 633 & 34.5 \\
\hline 3 & 1021 & 55.7 \\
\hline NA & 148 & 7.4 \\
\hline \multicolumn{3}{|l|}{ ER/PgR status } \\
\hline ER and/or PgR positive & 895 & 45.9 \\
\hline ER and PgR negative & 1057 & 54.1 \\
\hline NA & 29 & 1.5 \\
\hline \multicolumn{3}{|l|}{ HER2 status } \\
\hline IHC 3 & 1617 & 84.0 \\
\hline $\mathrm{IHC} \leq 2 \mathrm{FISH}+$ & 264 & 13.7 \\
\hline FISH + & 43 & 2.2 \\
\hline Not classified above & 57 & 2.9 \\
\hline Neoadjuvant therapy performed & 702 & 35.4 \\
\hline Adjuvant therapy performed & 1974 & 99.6 \\
\hline \multicolumn{3}{|l|}{ Trastuzumab administration } \\
\hline Preoperative only & 26 & 1.3 \\
\hline Pre- and postoperative & 440 & 22.2 \\
\hline Postoperative only & 1515 & 76.5 \\
\hline Hormonal therapy performed & 954 & 48.2 \\
\hline Surgery & 954 & 48.2 \\
\hline Partial mastectomy & 1021 & 51.6 \\
\hline Mastectomy & 959 & 48.4 \\
\hline NA & 1 & 0.1 \\
\hline Radiotherapy performed & 1139 & 57.5 \\
\hline
\end{tabular}

Table 1 (continued)

$L N$ lymph node, $E R$ estrogen receptor, $P g R$ progesterone receptor, IHC immunohistochemical staining, FISH fluorescence in situ hybridization, $N A$ not available

practice was evaluated, and the clinical issues based on the updated data from the JBCRG C-01 study were examined.

\section{Patients and study design}

An observational study was performed on patients aged over 20 years who were histologically diagnosed with invasive HER2-positive breast cancer stage I-III C and treated using TZM. Patients $(n=2024)$ from 56 institutions which participated in the Japan Breast Cancer Research Group (JBCRG) between July 2009 and June 2016 were registered in this study. All patients received perioperative TZM-containing therapy between January 2006 and June 2011 for at least 10 months. The data were finalized in August 2016. Fortythree patients who failed to meet the eligibility criteria were excluded and 1981 datasets were analyzed in this study.

The study protocol was approved by each institutional review board. We ensured that the subjects received a full explanation of the study according to the ethical guidelines for epidemiological studies and received their written informed consent or opt-out in accordance with the standards of the study centers. Data were managed by the Department of EBM Research, Institute for the Advancement of Clinical and Translational Science, Kyoto University Hospital, and the JBCRG Data Center. This study has been registered in the University Hospital Medical Information Network (UMIN), number UMIN000002737.

\section{Primary and secondary endpoints}

The endpoints in this study were previously described [5]. In brief, the primary and secondary endpoints were diseasefree survival (DFS) and overall survival (OS), respectively.

\section{Statistics}

The Kaplan-Meier method was used to estimate DFS and OS curves. The Chi-squared $\left(x^{2}\right)$ test or Wilcoxon tests for categorical data and log-rank test for time-to-event endpoints provided two-sided $p$ values, and a $p$ value $<0.05$ was considered significant. Cox regression analysis was used to estimate hazard ratios (HRs) and 95\% confidence intervals (CIs). Covariates used in the multivariate model were age, clinical tumor stage, clinical nodal stage, estrogen receptor (ER)/progesterone receptor (PgR) status, HER2 status, histological/nuclear grade, menopausal status, and past medical 
Table 2 Systemic treatment (in detail)

\begin{tabular}{|c|c|c|c|c|c|}
\hline \multirow{14}{*}{$\begin{array}{c}\text { Preoperative } \\
\text { therapy, } \\
\text { Yes:702 }\end{array}$} & \multicolumn{5}{|c|}{ Postoperative TZM, No:26 } \\
\hline & \multirow{13}{*}{$\begin{array}{l}\text { Postoperative } \\
\text { TZM, } \\
\text { Yes:676 }\end{array}$} & \multicolumn{4}{|c|}{ Postoperative CTx, Yes:53 } \\
\hline & & \multirow{12}{*}{$\begin{array}{l}\text { Postoperative } \\
\text { CTx, } \\
\text { No: } 623\end{array}$} & \multirow{5}{*}{$\begin{array}{l}\text { Preoperative } \\
\text { TZM, } \\
\text { No:208 }\end{array}$} & \multicolumn{2}{|c|}{ Preoperative CTx, AT:187 } \\
\hline & & & & \multicolumn{2}{|c|}{ Preoperative CTx, A-only: 10} \\
\hline & & & & \multicolumn{2}{|c|}{ Preoperative CTx, T-only:6 } \\
\hline & & & & \multicolumn{2}{|c|}{ Preoperative CTx, other:2 } \\
\hline & & & & \multicolumn{2}{|c|}{ Preoperative CTx, No:3 } \\
\hline & & & \multirow{7}{*}{$\begin{array}{l}\text { Preoperative } \\
\text { TZM, } \\
\text { Yes:415 }\end{array}$} & \multirow{2}{*}{$\begin{array}{l}\text { Preoperative } \\
\text { CTx, } \\
\text { AT:363 }\end{array}$} & $\begin{array}{l}\text { Concurrent with } \\
\text { CTx:338 }\end{array}$ \\
\hline & & & & & $\begin{array}{l}\text { Sequential with } \\
\text { CTx:25 }\end{array}$ \\
\hline & & & & \multirow{2}{*}{$\begin{array}{l}\text { Preoperative } \\
\text { CTx, } \\
\text { A-only:5 }\end{array}$} & Concurrent with CTx:4 \\
\hline & & & & & Sequential with CTx: 1 \\
\hline & & & & \multirow{2}{*}{$\begin{array}{l}\text { Preoperative } \\
\text { CTx, } \\
\text { T-only:45 }\end{array}$} & $\begin{array}{l}\text { Concurrent with } \\
\text { CTx:44 }\end{array}$ \\
\hline & & & & & Sequential with CTx:1 \\
\hline & & & & \multicolumn{2}{|c|}{ Preoperative CTx, other:2 } \\
\hline \multirow{13}{*}{$\begin{array}{c}\text { Preoperative } \\
\text { therapy, } \\
\text { No: } 1279\end{array}$} & \multirow{13}{*}{$\begin{array}{l}\text { Postoperative } \\
\text { TZM, } \\
\text { Yes:1279 }\end{array}$} & \multirow{5}{*}{\multicolumn{2}{|c|}{ Postoperative CTx, No (TZM monc }} & therapy):137 & \\
\hline & & & & Concurrent wi & Tx:242 \\
\hline & & & & Sequential wit & $T x: 282$ \\
\hline & & & & Other:2 & \\
\hline & & & & N.A.:2 & \\
\hline & & \multirow{8}{*}{$\begin{array}{l}\text { Postoperative } \\
\text { CTx, } \\
\text { Yes:1142 }\end{array}$} & \multirow{4}{*}{$\begin{array}{l}\text { Postoperative } \\
\text { CTx, } \\
\text { A-only:371 }\end{array}$} & \multicolumn{2}{|c|}{ Concurrent with CTx:1 } \\
\hline & & & & \multicolumn{2}{|c|}{ Sequential with CTx:367 } \\
\hline & & & & \multicolumn{2}{|l|}{ Other:2 } \\
\hline & & & & \multicolumn{2}{|l|}{ N.A.:1 } \\
\hline & & & Postoperative & \multicolumn{2}{|c|}{ Concurrent with CTx:100 } \\
\hline & & & CTx & \multicolumn{2}{|c|}{ Sequential with CTx:113 } \\
\hline & & & T-only:215 & \multicolumn{2}{|l|}{ Other:2 } \\
\hline & & & \multicolumn{3}{|c|}{ Postoperative CTx, other:28 } \\
\hline
\end{tabular}

$C T x$ chemotherapy, $A$ anthracycline, $T$ taxane

history. Statistical analyses were performed using SAS ver. 9.2 (SAS Institute).

\section{Results}

\section{Patient characteristics and treatment}

The median follow-up period was 80.9 (5.0-132.2, mean 80.2) months. Baseline characteristics and treatments are summarized in Table 1. The expression of ER, PgR, and HER2, and grade were determined using biopsy specimens before preoperative treatment from patients who received preoperative therapy or surgical specimens from patients without preoperative therapy.

Mastectomy was performed for 959 patients and breastconserving surgery for 1021 patients. A total of 1139 patients received postoperative radiotherapy and 954 patients received postoperative hormonal therapy. 

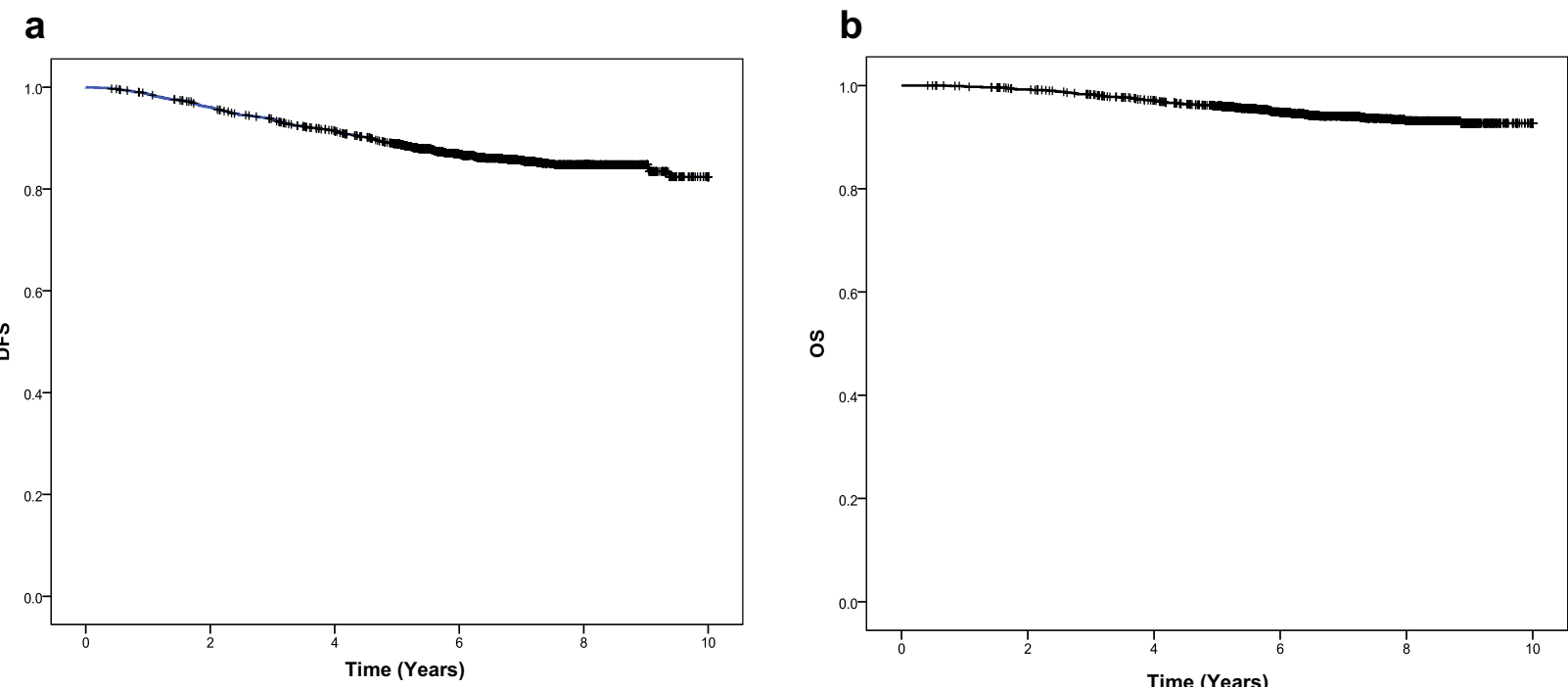

\begin{tabular}{|l|l|l|l|l|l|l|l|l|l|l|l|}
\hline DFS & $0 y$ & $1 y$ & $2 y$ & $3 y$ & $4 y$ & $5 y$ & $6 y$ & $7 y$ & $8 y$ & $9 y$ & $10 y$ \\
\hline No. at risk & 1981 & 1945 & 1885 & 1825 & 1752 & 1658 & 1256 & 806 & 397 & 145 & 34 \\
\hline DFS rate (\%) & & 98.6 & 96.1 & 93.7 & 91.4 & 88.9 & 86.9 & 85.6 & 84.8 & 84.8 & 82.4 \\
\hline 95\% Cl lower (\%) & & 98.1 & 95.2 & 92.6 & 90.2 & 87.5 & 85.4 & 83.9 & 83.0 & 83.0 & 79.2 \\
\hline $95 \%$ Cl upper (\%) & & 99.1 & 96.9 & 94.8 & 92.7 & 90.3 & 88.4 & 87.2 & 86.5 & 86.5 & 85.6 \\
\hline
\end{tabular}

\begin{tabular}{|l|l|l|l|l|l|l|l|l|l|l|l|}
\hline OS & 0y & $1 y$ & $2 y$ & $3 y$ & $4 y$ & $5 y$ & $6 y$ & $7 y$ & $8 y$ & $9 y$ & $10 y$ \\
\hline No. at risk & 1981 & 1970 & 1946 & 1908 & 1853 & 1780 & 1367 & 887 & 443 & 162 & 42 \\
\hline OS rate (\%) & & 99.8 & 99.2 & 98.3 & 97.1 & 96.0 & 94.8 & 94.1 & 93.2 & 92.7 & 92.7 \\
\hline 95\% Cl lower (\%) & & 99.7 & 98.9 & 97.7 & 96.4 & 95.1 & 93.8 & 93.0 & 91.8 & 91.1 & 91.1 \\
\hline 95\% Cl upper (\%) & & 100.0 & 99.6 & 98.8 & 97.9 & 96.9 & 95.8 & 95.2 & 94.5 & 94.3 & 94.3 \\
\hline
\end{tabular}

Fig. 1 a Disease-free survival (DFS) for all patients. b Overall survival (OS) for all patients

In this observational study assessing the common use of TZM, we did not predetermine the treatment protocol. In brief, of the 702 patients who received preoperative therapy, 415 received TZM preoperatively and 26 received only TZM preoperatively. A total of 1279 patients received postoperative systemic therapy only, and 137 patients received TZM monotherapy (Table 2).

\section{DFS and OS}

The 5- and 10-year DFS rates were 88.9 (95\% CI 87.5-90.3\%) and $82.4 \%$ (95\% CI 79.2-85.6\%), respectively. The 5- and 10-year OS rates were $96 \%$ (95\% CI 95.1-96.9\%) and $92.7 \%$ (95\% CI 91.1-94.3\%), respectively (Fig. 1a, b).

\section{Timing of recurrence with respect to organs}

We calculated the annual risk of first recurrence with respect to ER expression and sites (Fig. 2a-f). ER-negative disease often recurred earlier than ER-positive disease. With respect to the site of the first recurrence, the incidence of liver and lung metastasis reached a peak at $2-3$ years after surgery.
However, there was no peak in thoracic wall, supraclavicular, or parasternal lymph node recurrence after surgery, and a relatively high recurrence rate was continuously observed in a relatively late phase (5-7 years). The peak of brain metastasis was 1 year earlier than that of liver metastasis.

\section{Analysis of factors influencing DFS and a recurrence model}

Univariate analyses comparing subgroups were performed using the log-rank test; hazard ratios (HRs) with 95\% CIs were derived from Cox proportional hazards models (Table 3).

Multivariate analysis revealed the risk factors for recurrence to be an age of $\geq 70$ years, $T 2$ or larger tumors, clinically detected lymph node metastasis, histological tumor diameter of $>1 \mathrm{~cm}$, histologically detected lymph node metastasis $(\geq n 2)$, and the implementation of preoperative treatment. We prepared the risk score of recurrence based on the results of the multivariate analysis. When comparing the compulsive insertion method with the variableincreasing method using likelihoods, significant factors remained. Based on the coefficient calculated, the score 
Table 3 Univariate analysis

\begin{tabular}{|c|c|c|c|c|c|}
\hline & \multicolumn{5}{|c|}{ Univariate analysis } \\
\hline & $\mathrm{B}$ & SE & \multicolumn{2}{|c|}{$\begin{array}{l}\text { HR (95\% CI upper, } \\
\text { lower) }\end{array}$} & $p$ value \\
\hline \multicolumn{6}{|l|}{ Age } \\
\hline Per year, continuous & 0.012 & 0.006 & 1.012 & $1.000,1.023$ & 0.044 \\
\hline$<60$ vs. $\geq 60$ & 0.317 & 0.124 & 1.373 & $1.077,1.750$ & 0.011 \\
\hline$<70$ vs. $\geq 70$ & 0.745 & 0.183 & 2.107 & $1.471,3.019$ & $<0.001$ \\
\hline \multicolumn{6}{|l|}{ Menopausal status } \\
\hline Pre- vs. post-menopause & 0.041 & 0.127 & 1.042 & $0.812,1.337$ & 0.746 \\
\hline \multicolumn{6}{|l|}{ T stage } \\
\hline T1 vs. T2-4 & 0.950 & 0.162 & 2.586 & $1.884,3.552$ & $<0.001$ \\
\hline \multicolumn{6}{|l|}{$\mathrm{N}$ sage } \\
\hline N0 vs. N1-3 & 0.893 & 0.125 & 2.444 & $1.912,3.123$ & $<0.001$ \\
\hline \multicolumn{6}{|l|}{ Pathological tumor size } \\
\hline$\leq 1 \mathrm{~cm} \mathrm{vs} .>1 \mathrm{~cm}$ & 0.383 & 0.142 & 1.467 & $1.110,1.938$ & 0.007 \\
\hline \multicolumn{6}{|l|}{ Pathological lymph node metastasis } \\
\hline 0 vs. $1-3$ lymph nodes involved & 0.429 & 0.145 & 1.536 & $1.156,2.043$ & 0.003 \\
\hline $0 \mathrm{vs} . \geq 4$ lymph nodes involved & 1.152 & 0.149 & 3.164 & $2.365,4.233$ & $<0.001$ \\
\hline pN0 vs. pN + & 0.715 & 0.121 & 2.044 & $1.611,2.594$ & $<0.001$ \\
\hline \multicolumn{6}{|l|}{ Grade } \\
\hline Grade 1 vs. 2 & -0.085 & 0.224 & 0.918 & $0.592,1.424$ & 0.703 \\
\hline Grade 1 vs. 3 & -0.036 & 0.213 & 0.964 & 0.635 & 0.865 \\
\hline \multicolumn{6}{|l|}{ ER status } \\
\hline Negative vs. positive & -0.104 & 0.123 & 0.901 & $0.708,1.146$ & 0.396 \\
\hline \multicolumn{6}{|l|}{ HER2 status } \\
\hline IHC 3 +vs. 2 + FISH + & -0.023 & 0.180 & 0.977 & $0.687,1.389$ & 0.896 \\
\hline IHC 3 + vs. FISH+ & 0.321 & 0.360 & 1.378 & $0.681,2.790$ & 0.373 \\
\hline \multicolumn{6}{|l|}{ Surgery (type) } \\
\hline Partial vs. total mastectomy & 0.486 & 0.123 & 1.626 & $1.278,2.070$ & $<0.001$ \\
\hline \multicolumn{6}{|l|}{ Preoperative systemic therapy } \\
\hline No vs. Yes & 0.409 & 0.122 & 1.505 & $1.185,1.912$ & 0.001 \\
\hline CTx concurrent with TZM vs. sequential & 0.196 & 0.425 & 1.217 & $0.529,2.802$ & 0.644 \\
\hline CTx concurrent with TZM vs. without CTx & -9.998 & 230.841 & 0.000 & 0.000, inf & 0.965 \\
\hline \multicolumn{6}{|l|}{ Postoperative systemic therapy } \\
\hline No vs. yes & -1.956 & 0.504 & 0.141 & $0.053,0.380$ & $<0.001$ \\
\hline CTx concurrent with TZM vs. sequential & -0.006 & 0.182 & 0.994 & $0.696,1.419$ & 0.974 \\
\hline CTx concurrent with TZM vs. without CTx & 0.472 & 0.176 & 1.604 & $1.136,2.263$ & 0.007 \\
\hline \multicolumn{6}{|l|}{ Chemotherapy } \\
\hline No vs. yes (pre and/or postoperative) & -0.380 & 0.206 & 0.684 & $0.457, .025$ & 0.066 \\
\hline
\end{tabular}

$B$ regression coefficient, $S E$ regression coefficient of regression coefficient, $H R$ hazard ratio; $95 \% C I 95 \%$ confidence interval

ratio was calculated and the final score was determined by rounding off the values (Table 4 ). We calculated the 5-year recurrence risk for each total point (Table 5) and estimated the Kaplan-Meier curve for the DFS of each score (Fig. 3). The C-index was 0.653 .

\section{Discussion}

In Japan, perioperative treatment using trastuzumab has markedly improved the outcomes of HER2-positive breast cancer patients. Even with perioperative chemotherapy using 


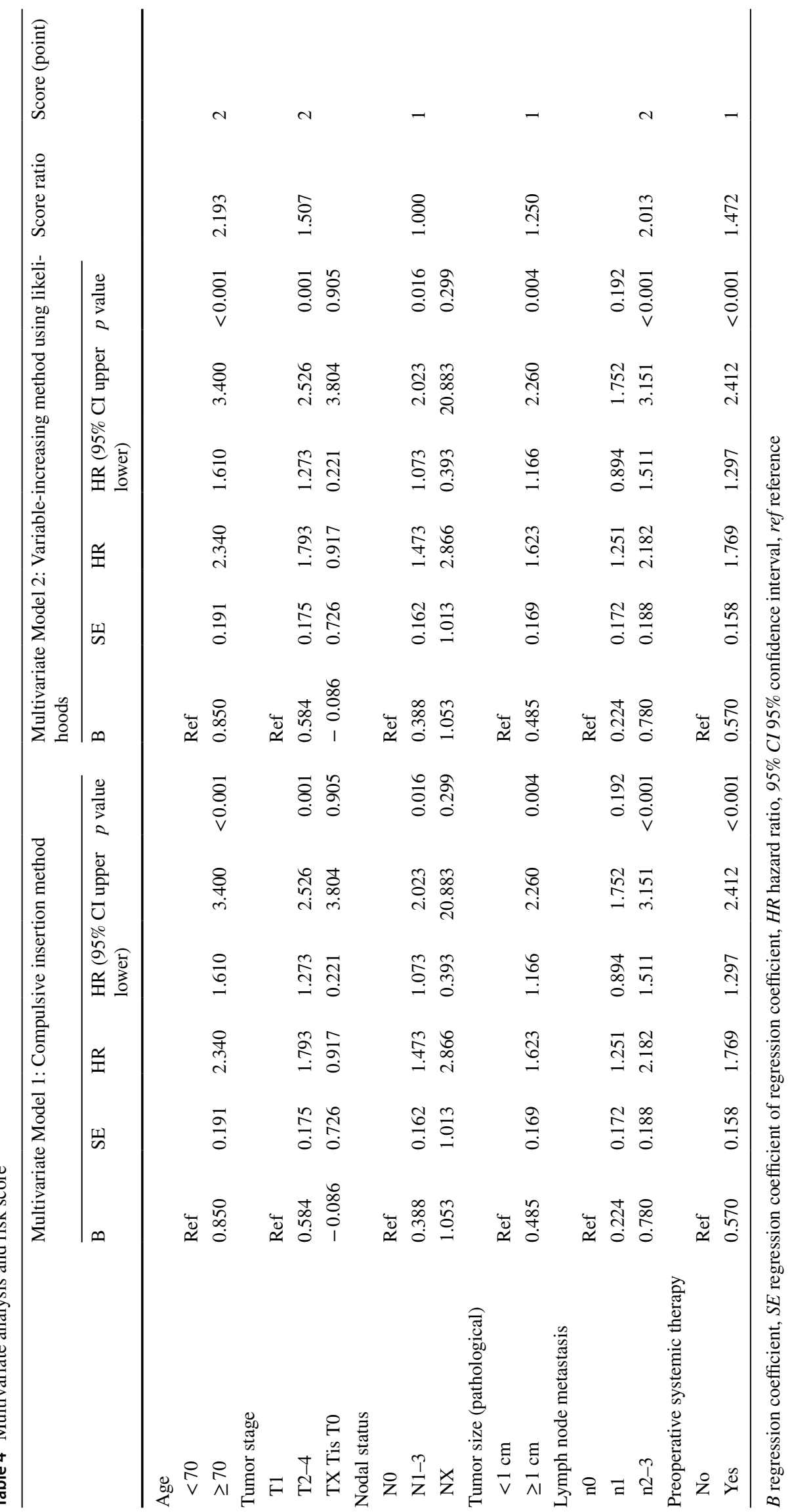


Table 5 Risk score and estimated 5-year recurrence risk for each total point

\begin{tabular}{ll}
\hline Variable & Risk point \\
\hline Age $\geq 70$ & 2 \\
T stage T2-4 & 2 \\
N stage N1-3 & 1 \\
Tumor size (pathological) $\geq 1 \mathrm{~cm}$ & 1 \\
Lymph node metastasis $(\geq \mathrm{n} 2)$ & 2 \\
Preoperative systemic therapy (yes) & 1 \\
\hline Total score & Probability $(\%)$ \\
\hline 0 & 3.5 \\
1 & 4.7 \\
2 & 6.4 \\
3 & 8.6 \\
4 & 11.6 \\
5 & 15.6 \\
6 & 21.1 \\
7 & 28.4 \\
8 & 38.4 \\
9 & 51.8 \\
\hline
\end{tabular}

anthracycline or taxanes, approximately $25 \%$ of patients with HER2-positive breast cancer developed recurrence before trastuzumab became commercially available [15]. These results are consistent with those in the placebo group in a phase III clinical study of perioperative pertuzumab therapy (APHINITY study) [9]. No new AEs related to TZM were detected in this study.

The present study had several limitations. This cohort study was a single-arm observational study of TZM with or without chemotherapy in daily practice; therefore, the treatment effectiveness and clinicopathological features, including HR and HER2 status, were assessed by physicians. Treatment selection by each physician, including the surgical procedure, radiotherapy, and chemotherapy, may have affected the outcomes. The need for chemotherapy, especially for patients over 70 years of age, was not significant in this study, but conclusions should be carefully held until results of a randomized study are available.

An age of $\geq 70$ years, grade of $\mathrm{T} 2$ or higher, clinically detected lymph node metastasis, histological tumor diameter of $\geq 1 \mathrm{~cm}$, and histologically detected lymph node metastasis were extracted as prognostic factors, similar to the previous report [5]. Subgroup analysis in the APHINITY trial [9] also demonstrated the additive effects of pertuzumab in patients with lymph node metastasis or elderly patients. In this analysis, our recurrence-predicting model included the clinical $\mathrm{N}$ stage and pathological nodepositive status. When employing the variable-increasing method with the likelihood ratio as mutually independent factors on multivariate analysis, these two factors remained.

Furthermore, the significance of histological node-positive status $(n)$ and pathological tumor size $(t)$ were suggested to depend on the presence of preoperative treatment; therefore, an additional subgroup analysis regarding the presence of preoperative treatment was performed. There was no preoperative treatment-related difference in the values on DFS of $n$ and $t$ (Supplement 1). Furthermore, we directly investigated the interaction between the presence of preoperative treatment and lymph node metastasis or pathological tumor size by analysis involving an interaction item, but it was insignificant. The influence of lymph node metastasis or pathological tumor size on DFS may be similar regardless of the presence of preoperative treatment. Indeed, even if preoperative chemotherapy results in pn0, the risk of recurrence was higher than if it was N0 before the start of treatment (Supplement 2).

In the guidelines, regular imaging, such as CT, is not recommended for asymptomatic patients [16]. In our study, the timing and annual risk of recurrent HER2-positive breast cancer were characterized by each organ. In particular, the start of treatment for recurrence in the phase of restricted tumor burden in patients with brain or bone metastases may minimize complications or treatment-related adverse effects. As the number of treatment options, such as pertuzumab [13] and T-DM1 [14], for metastatic or recurrent HER2positive breast cancer has recently increased, this should be reflected in follow-up plans [17].

Recently, perioperative therapy for HER2-positive EBC has been improved via attempts to eliminate anthracycline $[1,6,7]$, the development of anti-HER2 drugs with different actions, such as neratinib [8] and pertuzumab [9], and shortening of the trastuzumab administration period [10, 11]. If the risk of recurrence is high, the addition of pertuzumab or extension of neratinib treatment should be considered. Patients who fail to achieve pathological CR following neoadjuvant HER2-targeted therapy (along with chemotherapy) are also at increased risk for recurrence. For such patients, T-DM1 should be considered [18]. On the other hand, if the risk is low, treatment using short-term trastuzumab therapy may be successful. To optimize such treatment, it is necessary to comprehensively understand the risk of recurrence. Although the current staging is based on clinicopathological characteristics, our findings suggest that host factors, such as age, are included. Our recurrence model may be useful for future studies after validation. 

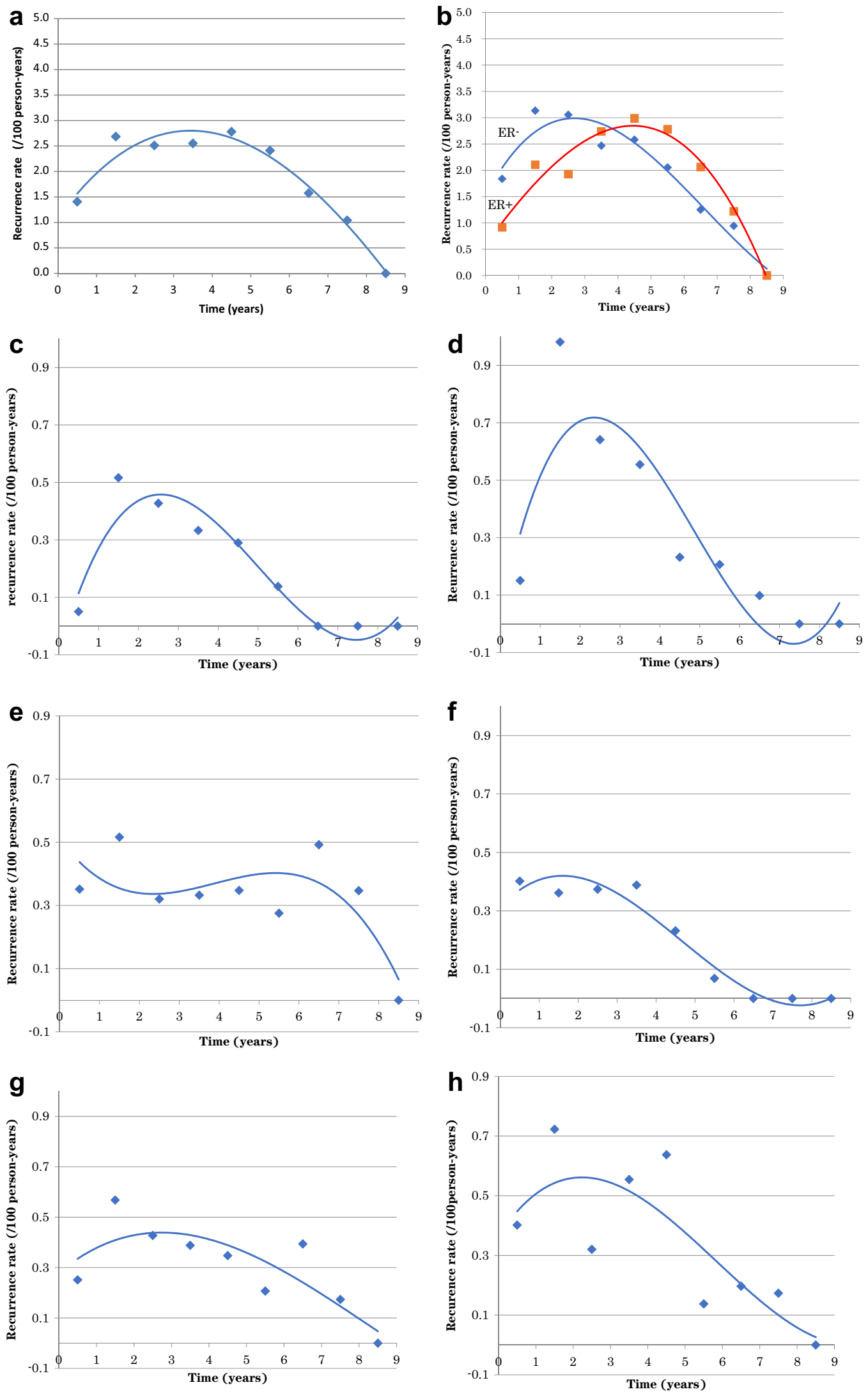

Fig. 2 Annual hazard of recurrence. a All. b Stratified by ER status. c-h Stratified by first recurrence site, $\mathbf{c}$ liver, d lung, e chest wall, supraclavicular lymph node, and para sternal lymph node, $\mathbf{f}$ brain, $\mathbf{g}$ bone, $\mathbf{h}$ ipsilateral breast and axillary lymph node 


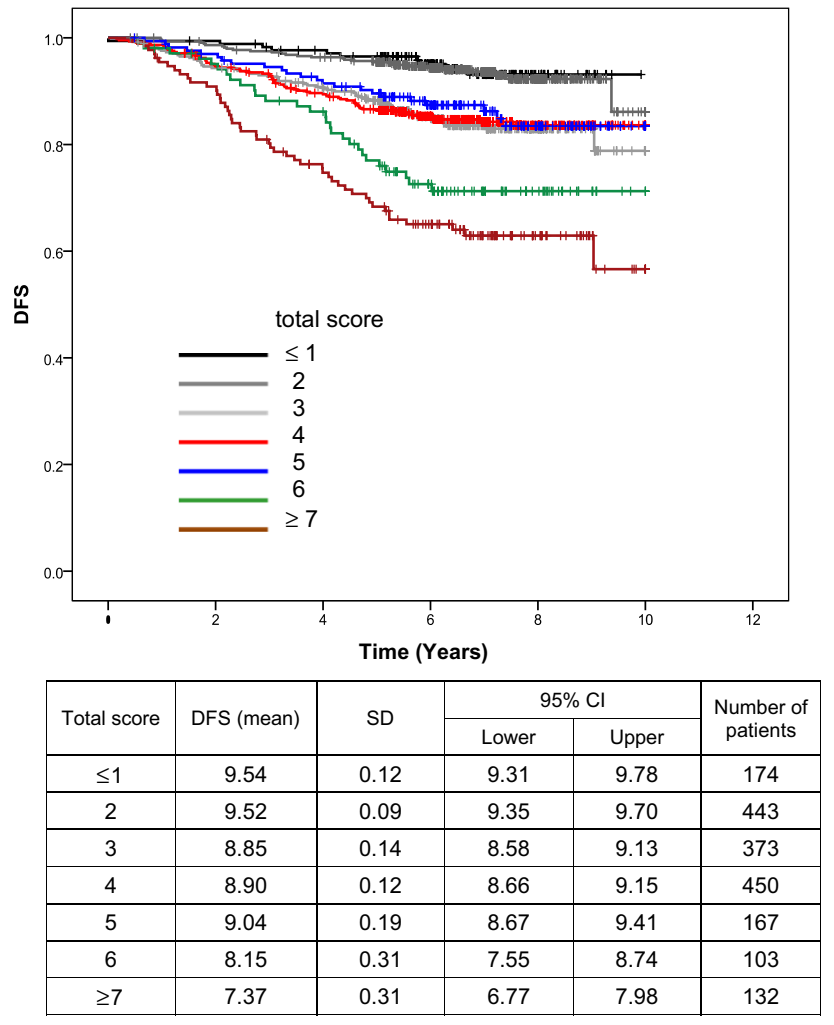

Fig. 3 Estimated DFS of each score

\section{Conclusion}

As this recurrence model was created based on the data from an observational study, validation is necessary. However, it may facilitate calculation of the risk of recurrence, thereby improving treatment selection.

Acknowledgements The authors are grateful to all of the co-investigators and patients for their cooperation in the JBCRG C-01 study. The authors also thank the following additional investigators for their contributions to this study: K. Yamagami (Shinko Hospital), T. Morimoto (Yao Municipal Hospital), Y. Hasegawa (Hirosaki Municipal Hospital), H. Shigematsu (Hiroshima University Hospital), M. Hosoda (Hokkaido University Hospital), H. Abe (Bell Land General Hospital), D. Yotsumoto (Social Medical Corporation Hakuaikai Sagara Hospital), H. Tanino (Kitasato University Hospital), Y. Yamamoto (Kumamoto University Hospital), K. Hisamatsu (Oikawa Hospital), T. Aihara (Aihara Hospital), H. Bando (University of Tsukuba Hospital), H. Yoshibayashi (Japanese Red Cross Wakayama Medical Center), N. Tagaya (Dokkyo Medical University), H. Doihara (Okayama University Hospital), K. Narui (Yokohama City University Medical Center), H. Mukai (National Cancer Center Higashi Hospital), K. Aogi (National Hospital Organization Shikoku Cancer Center), S. Tsuyuki (Osaka Red Cross Hospital), Y. Kawabuchi (Hiroshima General Hospital), Y. Wada (National Hospital Organization Himeji Medical Center), Y. Kakugawa (Miyagi Cancer Center), Y. Moriguchi (Kyoto City Hospital), Y. Kawaguchi (Murakami Memorial Hospital Asahi University), H. Suwa (Hyogo Prefectural Tsukaguchi Hospital), F. Tanaka (Fukui Red Cross Hospital), H. Nakagomi (Yamanashi Prefectural Central Hospital), T. Ito (Rinku General Medical Center), S. Nakamura (Showa University Hospital), H.
Takeuchi (Beppu Medical Center), M. Inokuchi (Kanazawa University Hospital), Y. Teramura (Hikone Municipal Hospital), K. Ito (Shinshu University School of Medicine), S. Sato (Ichinomiya Municipal Hospital), F. Yotsumoto (Shiga Medical Center for Adults), T. Okino (Kohka Public Hospital), Y. Mitsudo (Mitsubishi Kyoto Hospital), K. Yoshidome (Osaka Police Hospital), and Y. Tokunaga (Osakakita Teishin Hospital). The authors also thank the following additional investigators for their contributions to this study: Tetsuo Takeuchi and Yosuke Sasaki for statistical work, Sachiko Inoue and Miyoko Hasebe for data management, and Kiyomi Kashiwa and Nobuko Aoki for secretarial work. This study was conducted using our own funds from JBCRG. The Department of EBM Research, Institute for Advancement of Clinical and Translational Science was partially funded by Chugai Pharmaceutical Co., Ltd.

Author contributions Study concept: HY, HI, NM, SO, MT. Study design: HY, HI, NM, SO, MT. Data acquisition: all authors. Quality control of data and algorithms: HY, KK, TT. Data analysis and interpretation: SY, HI, NM, SO, MT. Statistical analysis: SM. Manuscript preparation: HY, NY, RN, SO, NS, MT, TK. Manuscript editing: HY, KY, TS, MK, TL. Manuscript review: all authors.

\section{Compliance with ethical standards}

Conflict of interest 1 Dr. Yamashiro reports personal fees from Chugai, personal fees from Daiich-Sankyo, personal fees from Pfizer, personal fees from Kyowa Kirin, personal fees from Eisai, personal fees from Eli Lilly, personal fees from Takeda, and personal fees from Taiho outside the submitted work. 2 Dr. Iwata reports grants and personal fees from Chugai during the conduct of the study, and grants and personal fees from Novartis, grants and personal fees from AstraZeneca, grants and personal fees from Pfizer, grants and personal fees from Eli Lilly, grants and personal fees from Daiichi Sankyo, grants from MSD, personal fees from Eisai, grants and personal fees from Kyowa Kirin, and grants from Byer outside the submitted work. Dr Iwata is a member of an organized committee in the Japan Breast Cancer Research Group. 3 Dr. Masuda reports grants, personal fees and other from Chugai, personal fees and other from AstraZeneca, personal fees and other from Pfizer, personal fees and other from Eli Lilly, grants, personal fees and other from Eisai, personal fees and other from Takeda, personal fees and other from Kyowa Kirin, other from MSD, personal fees and other from Novartis, and personal fees and other from Daiichi Sankyo outside the submitted work. 4 Dr. Yamamoto reports other from the Japan Breast Cancer Research Group during the conduct of the study, and other from MSD, other from Eli Lilly, and other from Nippon Kayaku outside the submitted work. 5 Dr. Nishimura reports personal fees from Pfizer, personal fees from Novartis, and personal fees from Chugai outside the submitted work. 6 Dr. Ohtani reports personal fees from Chugai, personal fees from AstraZeneca, personal fees from Eisai, personal fees from Pfizer, and personal fees from Eli Lilly outside the submitted work. 7 Dr. Sato reports personal fees from Chugai, personal fees from Eisai, personal fees from Pfizer, and personal fees from Taiho outside the submitted work. 8 Dr. Takahashi reports personal fees from AstraZeneca, grants and personal fees from Chugai, grants and personal fees from Eisai, personal fees from Eli Lilly, grants and personal fees from Kyowa Kirin, grants and personal fees from Nippon Kayaku, personal fees from Novartis, personal fees from Pfizer, and grants and personal fees from Taiho outside the submitted work. 9 Dr. Kamio has nothing to disclose. 10 Dr. Yamazaki has nothing to disclose. 11 Dr. Saito reports personal fees from Pfizer, personal fees from AstraZeneca, personal fees from Nippon Kayaku, and personal fees from Chugai outside the submitted work. 12 Dr. Kato has nothing to disclose. 13 Dr. Lee has nothing to disclose. 14 Dr. Kuroi reports personal fees from Taiho, Kyowa Kirin, Astellas, Eisai, and Novartis outside the 
submitted work, and from the Board of directors: Japan Breast Cancer Research Group Organization, Japan Breast Cancer Research Group Association. 15 Dr. Takano reports grants and personal fees from Daiichi Sankyo, grants and personal fees from Kyowa Kirin, grants and personal fees from Eisai, grants from Ono, grants from MSD, grants from Merck Serono, grants from Taiho, grants from Novartis, grants from Chugai, personal fees from Pfizer, and personal fees from Eli Lilly outside the submitted work. 16 Dr. Yasuno has nothing to disclose. 17 Dr. Morita reports personal fees from AstraZeneca, personal fees from Bristol-Myers Squibb, personal fees from Chugai, personal fees from Eisai, personal fees from Eli Lilly, personal fees from MSD, personal fees from Pfizer, and personal fees from Taiho outside the submitted work. 18 Dr. Ohno reports grants and personal fees from Eisai, personal fees from Chugai, personal fees from Pfizer, grants and personal fees from Taiho, personal fees from Nippon Kayaku, personal fees from Kyowa Kirin, personal fees from Novartis, personal fees from AstraZeneca, and personal fees from Eli Lilly outside the submitted work. 19 Dr. Toi reports grants and personal fees from Chugai during the conduct of the study, and grants and personal fees from Taiho, grants and personal fees from Takeda, grants and personal fees from Shimadzu, grants and personal fees from Eisai, grants, personal fees and other from Daiichi Sankyo, personal fees from Yakult, grants, personal fees and other from Kyowa Kirin, personal fees and other from Konica-Minolta, grants and personal fees from Pfizer, personal fees from Eli Lilly, personal fees from MSD, personal fees and other from Genomic Health, grants and personal fees from AstraZeneca, personal fees from Novartis, personal fees from Bayer, personal fees from Sanofi, grants and personal fees from C\&C Res Lab, grants and personal fees from Nippon Kayaku, grants from Bizcom Japan, grants from AFI technologies, grants and non-financial support from the Japan Breast Cancer Research Group Association, grants from Astellas, grants from DSK, non-financial support from the Organisation for Oncology and Translational Research, grants and non-financial support from the Kyoto Breast Cancer Research Network, grants from Terumo, and other from BMS outside the submitted work.

Ethical approval All procedures performed in studies involving human participants were in accordance with the ethical standards of the institutional and/or national research committee, and with the 1964 Helsinki Declaration and its later amendments or comparable ethical standards.

Open Access This article is licensed under a Creative Commons Attribution 4.0 International License, which permits use, sharing, adaptation, distribution and reproduction in any medium or format, as long as you give appropriate credit to the original author(s) and the source, provide a link to the Creative Commons licence, and indicate if changes were made. The images or other third party material in this article are included in the article's Creative Commons licence, unless indicated otherwise in a credit line to the material. If material is not included in the article's Creative Commons licence and your intended use is not permitted by statutory regulation or exceeds the permitted use, you will need to obtain permission directly from the copyright holder. To view a copy of this licence, visit http://creativecommons.org/licenses/by/4.0/.

\section{References}

1. Slamon D, Eiermann W, Robert N, et al. Adjuvant trastuzumab in HER2-positive breast cancer. N Engl J Med. 2011;365:1273-83.

2. Perez EA, Romond EH, Suman VJ, et al. Four-year follow-up of trastuzumab plus adjuvant chemotherapy for operable human epidermal growth factor receptor 2-positive breast cancer: joint analysis of data from NCCTG N9831 and NSABP B-31. J Clin Oncol. 2011;29:3366-73.

3. Spielmann M, Roche H, Delozier T, et al. Trastuzumab for patients with axillary-node-positive breast cancer: results of the FNCLCCPACS 04 trial. J Clin Oncol. 2009;27:6129-34.

4. Gianni L, Dafni U, Gelber RD, et al. Treatment with trastuzumab for 1 year after adjuvant chemotherapy in patients with HER2positive early breast cancer: a 4-year follow-up of a randomised controlled trial. Lancet Oncol. 2011;12:236-44.

5. Yamshiro H, Iwata H, Masuda N, et al. Outcomes of trastuzumab therapy in HER2-positive early breast cancer patients. Int J Clin Oncol. 2015;20:709-22.

6. Tolaney SM, Barry WT, Dang CT, et al. Adjuvant paclitaxel and trastuzumab for node-negative, HER2-positive breast cancer. N Engl J Med. 2015;372:134-41.

7. Jones SE, Collea R, Paul D, et al. Adjuvant docetaxel and cyclophosphamide plus trastuzumab in patients with HER2-amplified early stage breast cancer: a single-group, open-label, phase 2 study. Lancet Oncol. 2013;14:1121-8.

8. Martin M, Holmes FA, Ejlertsen B, et al. Neratinib after trastuzumab-based adjuvant therapy in HER2-positive breast cancer (ExteNET): 5-year analysis of a randomised, double-blind, placebo-controlled, phase 3 trial. Lancet Oncol. 2017;18:1688-700.

9. von Minckwitz G, Procter M, de Azambuja E, et al. Adjuvant Pertuzumab and Trastuzumab in early HER2-positive breast cancer. N Engl J Med. 2017;377:122-31.

10. Joensuu H, Bono P, Kataja V, et al. Fluorouracil, epirubicin, and cyclophosphamide with either docetaxel or vinorelbine, with or without trastuzumab, as adjuvant treatments of breast cancer: final results of the FinHer Trial. J Clin Oncol. 2009;27:5685-92.

11. Pivot X, Romieu G, Debled M, et al. 6 months versus 12 months of adjuvant trastuzumab for patients with HER2-positive early breast cancer (PHARE): a randomised phase 3 trial. Lancet Oncol. 2013;14:741-8.

12. Earl HM, Hiller L, Vallier AL, et al. 6 versus 12 months of adjuvant trastuzumab for HER2-positive early breast cancer (PERSEPHONE): 4-year disease-free survival results of a randomised phase 3 non-inferiority trial. Lancet. 2019;393:2599-612.

13. Baselga J, Cortes J, Kim SB, et al. Pertuzumab plus trastuzumab plus docetaxel for metastatic breast cancer. N Engl J Med. 2012;366:109-19.

14. Verma S, Miles D, Gianni L, et al. Trastuzumab emtansine for HER2-positive advanced breast cancer. N Engl J Med. 2012;367:1783-91.

15. Yamashiro H, Takada M, Nakatani E, et al. Prevalence and risk factors of bone metastasis and skeletal related events in patients with primary breast cancer in Japan. Int J Clin Oncol. 2013;19:852-62.

16. Schnipper LE, Smith TJ, Raghavan D, et al. American Society of Clinical Oncology identifies five key opportunities to improve care and reduce costs: the top five list for oncology. J Clin Oncol. 2012;30:1715-24.

17. Runowicz CD, Leach CR, Henry NL, et al. American Cancer Society/American Society of Clinical Oncology Breast Cancer Survivorship Care Guideline. J Clin Oncol. 2016;34:611-35.

18. Minckwitz G, Huang CS, Mano MS, et al. Trastuzumab emtansine for residual invasive HER2-positive breast cancer. N Engl J Med. 2018;380:617-28.

Publisher's Note Springer Nature remains neutral with regard to jurisdictional claims in published maps and institutional affiliations. 


\section{Affiliations}

\section{Hiroyasu Yamashiro ${ }^{1}$ - Hiroji Iwata ${ }^{2} \cdot$ Norikazu Masuda $^{3} \cdot$ Naohito Yamamoto $^{4} \cdot$ Reiki Nishimura $^{5}$. Shoichiro Ohtani ${ }^{6} \cdot$ Nobuaki Sato $^{7} \cdot$ Masato Takahashi $^{8} \cdot$ Takako Kamio $^{9} \cdot$ Kosuke Yamazaki $^{10} \cdot$ Tsuyoshi Saito $^{11}$. Makoto Kato ${ }^{12} \cdot$ Tecchuu Lee $^{13} \cdot$ Katsumasa Kuroi $^{14} \cdot$ Toshimi Takano $^{15} \cdot$ Shinji Yasuno ${ }^{16} \cdot$ Satoshi Morita ${ }^{17}$. Shinji Ohno ${ }^{18} \cdot$ Masakazu Toi $^{19}$}

Hiroji Iwata

hiwata@aichi-cc.jp

Norikazu Masuda

nmasuda@alpha.ocn.ne.jp

Naohito Yamamoto

nyamamot@chiba-cc.jp

Reiki Nishimura

nishimura-r@k-shinto.or.jp

Shoichiro Ohtani

sho_ohtani@hotmail.com

Nobuaki Sato

nobus@niigata-cc.jp

Masato Takahashi

masato.takahashi0725@gmail.com

Takako Kamio

kamio.takako@twmu.ac.jp

Kosuke Yamazaki

kosyama@rchokkaido-cn.ac.jp

Tsuyoshi Saito

tsaito@jcom.home.ne.jp

Makoto Kato

k-chappy@symphony.plala.or.jp

Tecchuu Lee

chol-joo-lee@kyoto1-jrc.org

Katsumasa Kuroi

kurochan@dd.iij4u.or.jp

Toshimi Takano

takano@toranomon.gr.jp

Shinji Yasuno

syasuno@kuhp.kyoto-u.ac.jp

Satoshi Morita

smorita@kuhp.kyoto-u.ac.jp

Shinji Ohno

shinji.ohno@jfcr.or.jp

Masakazu Toi

toi@kuhp.kyoto-u.ac.jp

1 Department of Breast Surgery, Tenri Hospital, 200 Mishima-cho, Tenri, Nara 632-8552, Japan

2 Department of Breast Oncology, Aichi Cancer Center Hospital, 1-1 Kanokoden, Chikusa-ku, Nagoya, Aichi 464-8681, Japan

3 Surgery, Breast Oncology, National Hospital Organization Osaka National Hospital, 2-1-14 Hohenzaka, Chuo-ku, Osaka 540-0006, Japan
4 Division of Breast Surgery, Chiba Cancer Center, 666-2 Nitona-cho, Chuo-ku, Chiba 260-8717, Japan

5 Department of Breast Oncology, Kumamoto Shinto General Hospital, 3-2-65 Oe, Chuo-ku, Kumamoto City, Kumamoto 862-8655, Japan

6 Division of Breast Surgery, Hiroshima City Hiroshima Citizens Hospital, 7-33 Motomachi, Naka-ku, Hiroshima-shi, Hiroshima 730-8518, Japan

7 Department of Breast Oncology, Niigata Cancer Center Hospital, 2-15-3 Kawagishi town, Chuo-ku, Niigata 951-8566, Japan

8 Department of Breast Surgery, NHO Hokkaido Cancer Center, 4-2 Kikusui, Shiroishi-ku, Sapporo, Hokkaido 003-0804, Japan

9 Department of Breast, Endocrine and Pediatric Surgery, Tokyo Women's Medical University, 8-1 Kawadacho, Shinjuku-ku, Tokyo 162-8666, Japan

10 Japanese Red Cross Hokkaido College of Nursing, 664-1 Akebono-cho, KitamiKitami, Hokkaido 090-0011, Japan

11 Department of Breast Surgery, Japanese Red Cross Saitama Hospital, 1-5 Shintoshin, Chuo-ku, Saitama-shi, Saitama 330-8553, Japan

12 Kato Breast Surgery Clinic, 8-12 Nishiojicho, Kusatsu, Shiga 525-0037, Japan

13 Department of Breast Surgery, Japanese Red Cross Kyoto Daiichi Hospital, 15-749 Honmachi, Kyoto Higashiyama-ku, Kyoto 605-0981, Japan

14 Department of Breast Surgery, Tokyo Metropolitan Cancer and Infectious Diseases Center Komagome Hospital, 3-18-22 Honkomagome, Bunkyo-ku, Tokyo 113-8677, Japan

15 Department of Medical Oncology, Toranomon Hospital, 2-2-2 Toranomon, Minato-ku, Tokyo 105-8470, Japan

16 Department of EBM Research, Institute for Advancement of Clinical and Translational Science, Kyoto University Hospital, 54 Kawaharacho, Shogoin, Sakyo-ku, Kyoto 606-8507, Japan

17 Department of Biomedical Statistics and Bioinformatics, Kyoto University Graduate School of Medicine, 54 Kawaharacho, Shogoin, Sakyo-ku, Kyoto 606-8507, Japan

18 Breast Oncology Center, The Cancer Institute Hospital of JFCR, 3-8-31, Ariake, Koto-ku, Tokyo 135-8550, Japan

19 Breast Cancer Unit, Kyoto University Hospital, 54 Kawaharacho, Shogoin, Sakyo-ku, Kyoto 606-8507, Japan 